V. Aus dem Pharmakologischen Institut zu Bonn.

\title{
Zur Desinfectionsfrage.
}

Von Dr. J. Geppert, Privatdocenten und Assistenten am Pharmakologischen Institut.

(Fortsetzung aus No. 25.)

Die Fälle, in welchen das Thierexperiment weiter reichte, als dic Cultur, waren folgende: 1) Bei Desinfection vou Suspensiouen der Milzbrandsporen durch Snblimat 1:1000 und uachheriger Niederschlagnug des Sublimats durch Schwefelammon. 2) Unter ïhnlichen Umständen (unr mit schwächerer Sublimatlösung) bei Milzbrandbacillen. 3) Bei Sporenfäden, die in Chlorkalk und Salzsämre nnd dann iu Wasser gelegen hatten. 4) Bei Hantstücken, die nit Sporen inficirt waren, dann in Chlorkalk und Salzsäure, sowie in verdiinntem Ammoniak gelegen hatten. 
Dann möchte ich hier einige Beobachtungen anschliessen, die ich zufällig in der letzten Zeit gemacht habe. Ich kam zu ihnen folgendermaassen: Hat man eine Sporensuspension in Sublimat gelegt, und das Sublimat mit Schwefelammonium niedergeschlagen, so ist diese Lösung für Mäuse sehr giftig. Daher setzte ich, um die Giftwirkung zu vermeiden, dieser Lösung Salzsäure zu bis zur sauren, und dann Soda bis zur alkalischen Reaction. Mit diesen Mischungen wurde dann auf Cultur und Mäuse geimpft. . Die Resultate der Impfungen mit diesen Lösungen geben die Protokolle.

Reihe 1. $10 \mathrm{ccm}$ filtrirte Sporensuspension und $10 \mathrm{ccm}$ Sublimat werden gemischt; nach 1 $1 / 2$ Stunde wird ein Tropfen concentrirte Schwefelammoniumlösung zugefügt, und nun werden $0,7 \mathrm{ccm}$ herausgenommen und mit $8 \mathrm{ccm}$ Agargelatine gemischt. Der Rest wird mit Salzsäure angesăuert, $0,7 \mathrm{ccm}$ zur Cultur genommen, $1-2 \mathrm{ccm}$ einer Maus eingespritzt. Dann wird der Rest mit Sodalösung schwach alkalisch gemacht und wieder Cultur angelegt. Das Ergebniss war: Auf der ersten Cultur wuchsen in 24 Stunden etwa 60 Colonieen, auf der zweiten und dritten nichts. (Nachimpfung mit normalem Milzbrand ergab in 24 Stunden üppiges Wachsthum.) Die Maus starb am zweiten Tage an Milzbrand.

Reihe 2. Versuchsanordnung, wie bei der vorigen Reihe. Nachdem Schwefelammonium zugefügt, wird mit Salzsäure angesäuert, und Cultur (wie eben) angelegt, dann mit Soda die Lösung schwach alkalisch gemacht und Cultur angelegt, sowie auf eine Maus abgeimpft. Die Cultur aus der sauren Lösung zeigte nach 24 Stunden eine Anzahl Colonieen, die aus der alkalischen blieb steril. (Nachimpfung mit normalem Milzbrand ergab in 24 Stunden üppiges Wachsthum.) Die Maus starb nach drei Tagen an Milzbrand.

Endlich gehören auch noch zwei Versuche hierher, die spăter ausführlich mitgetheilt werden sollen (Reihe 10 und 12). In diesen Reihen wurde Sublimatserum $(1: 1000)$ mit Sporen gemischt, nach 24 Stunden das Sublimat mit Schwefelammon niedergeschlagen, dann die Flüssigkeit mit Salzsäure angesăuert, und nun abgeimpft auf Cultur und Thiere. Die Thiere starben an Milzbrand, die Culturen blieben steril. Nachimpfung der sterilen Culturen mit normalem Milzbrand ergab üppiges Wachsthum.

Jede sterile Cultur wurde 6 Tage beobachtet, ehe die Nachimpfung vorgenominen wurde. Die verwandte Schwefelammoniumlösung war aus 10\% igem Ammoniak durch Einbringen von fein vertheiltem Schwefel und Einleiten von Schwefelwasserstoff bis zur Absättigung des Ammoniaks bereitet. $1 \mathrm{ccm}$ schlug $0,8 \mathrm{~g}$ Schwefelblei aus essigsaurem Blei nieder.

Es ergiebt sich: Sobald die schwefelannmonhaltige Lösung durch Salzsäure sauer und eventuell durch Soda wieder alkalisch gemacht war, inficirten die in ihr enthaltenen Sporen zwar noch Thiere, aber gediehen nicht mehr auf Culturen.

Die Deutung einer grossen Zahl der angeführten Beobachtungen kann kaum zweifelhaft sein: Mit den Sporen zusammen wurden Spuren chemischer Kölper verimpft, die auf diese vergifteten Sporen entwicklungshemmend wirkten. Dass dies geschehen würde, liess sich a priori gar nicht voraussehen, denn, wie gezeigt, wächst normaler Milzbrand auf den so verunreinigten Nährböden sehr gut, und das Haupthinderniss für ein Auswachsen der Sporen in Cultur, das Sublimat, war, wo es in Frage kam, beseitigt. Gegen eine solche Eventualität bietet die Cultur keinen Schutz. Angenommen, sie bleibt steril, so kann es an mitverimpften Stoffen oder aber auch am Nährboden selbst von vornherein liegen: denn auch dieser ist ja nur ein künstlich hergestelltes Gemenge. Der Thierkörper aber hat, bis zu einem gewissen Grade wenigstens, die Fähigkeit, mitverimpfte Stoffe zu resorbiren. Nun werden die Sporen frei, und wenn überhaupt noch eine Möglichkeit der Infection besteht, dann kann sie jetzt erfolgen.

Nach solchen Betrachtungen möchte es beinahe scheinen, als wenn nun die von mir eingeführte Methodik, das ursprüngliche Desinficiens niederzuschlagen, überflüssig sei; denn man ersetzt doch eventuell nur ein entwickelungshemmendes Mittel durch ein anderes. Indess die Berechtigung eines solchen Einwandes ist doch nur eine scheinbare. Denn ich ersetze allerdings das eine entwickelungshemmende Mittel durch ein anderes; aber die Ersetzung hat nur dann Werth, wenn es mir auf diese Weise gelingt, länger entwickelungsfähige Sporen etc. nachzuweisen, mit anderen Worten, wenn es gelingt, das eine entwickelungshemmende Mittel durch ein anderes von geringerer Kraft abzulösen. Nun aber ist z. B. das Sublimat ein entwickelungshemmendes Mittel von solcher Stärke, dass jede Spur von den Sporen entfernt sein muss, damit sie auskeimen könnell. Daher kann es kommen, dass, wenn man Sublimat und Sporen zusammen in den Thierkörper einspritzt, dann keine Infection erfolgt; offenbar, weil eine so lange Zeit vergeht, bis alles Sublimat resorbirt resp. umgewandelt ist, dass in der Zwischenzeit bereits die Sporen ihre Infectionsfähigkeit verloren haben. Schlägt man aber das Sublimat nieder und spritzt es nun eventuell mit einem alldern schwächer entwickelungshemmenden Körper zusammen ein, so kann doch Infection erfolgen, weil, wenn erst ein gewisses Quantum von diesem resorbirt ist, dann jetzt die Infection erfolgen kann. Aber, und das möchte ich hier auch hervorheben, eine ganz absolute Sicherheit ist nicht zu schaffen. Man kann ihr aber auf cinem audern Wege sehr nahe kommen: Wenn man nämlich, wio ich es beim Chlor that, dieses auf die verschiedensten Weisen aus- fällt, und dann immer nach einer bestimmten Zeit keine Infectionen (und keine Cultur) erlangt, dann ist die Sicherheit eine so grosse, wie wir sie eben geben können.

Also um zu resümiren: Angenommen, man hat ein Object mit Desinfectionsmitteln etc. behandelt, und es liefert keine Cultur mehr auf künstlichem Nährboden, so ist damit nicht bewiesen, dass es seine Infectionsfähigkeit verloren habe. Denn es können sich in der Cultur entwickelungshemmende Substanzen finden, deren Anwesenheit wir nicht a priori erkennen können. Daher ist das Thierexperiment ein durchaus nothwendiger Theil jedes Desinfectionsnach weises.

Bei den Versuchen, in welchen das Sublimat durch Schwefelammon niedergeschlagen war, wirkt dann noch ein anderes Moment in der gleichen Richtung mit.

Legt man nämlich eine Cultur an, so wird man nicht zuviel Flüssigkeit einimpfen, um nicht den Nährboden zu verderben. Dieses Bedenken fällt beim Thier weg; man kann da grössere Mengen (sofern nicht Vergiftung eintritt) einspritzen. Wenn nun, wie es gegen Ende der Desinfection vorkommt, die Anzahl der entwickelungsfähigen Keime sehr gering wird, dann ist es viel bequemer, sich durch einen Thierversuch zu überzeugen, ob noch Infection eintritt, als eine grössere Anzahl Culturen anzulegen. Derartige Fälle kommen in der That vor. Einen der charakteristischsten, den ich bei Gelegenheit weiter unten publicirter Versuche beobachtet habe, möchte ich hier mittheilen.

Reihe $3 . \quad 3 \mathrm{ccm}$ filtrirter Sporensuspension werden mit $18 \mathrm{ccm}$ Sublimat $1: 500$ und $7 \mathrm{ccm}$ Wasser gemischt, nach $1 \frac{1 / 2}{2}$ Stunde mit 3 Tropfen concentrirter Schwefelammoniumlösung versetzt, und nun $0,7 \mathrm{ccm}$ auf eine Cultur, und etwa $4 \mathrm{ccm}$ auf ein Meerschweinchen verimpft. Der Rest wird aufbewahrt. Das Meerschweinchen stirbt am vierten Tage an Milzbrand. Die Cultur bleibt steril. Nun werden am vierten Tage angelegt 4 Culturen mit je $1,5 \mathrm{ccm}$ des Restes der Suspension. Auf einer Cultur wächst eine Colonie Milzbrand.

Einem Meerschweinchen werden ferner 1 bis $2 \mathrm{ccm}$ eingespritzt; es bleibt gesund.

Aus Experimenten dieser Art kann man einen für das Folgende wichtigen Schluss ziehen, dass nämlich nach Desinfection mit Sublimat und Entfernung des Sublimats durch Schwefelammonium auch noch die letzten Sporen, die durch das angewandte Culturverfahren nachweisbar waren, inficirten. Zum selben Schluss führt folgende Reihe:

Reihe 4. $8 \mathrm{ccm}$ Sublimat 1:1000 werden mit $1,5 \mathrm{ccm}$ einer filtrirteu Sporensuspension gemischt. Nach 2 Stunden werden 2 'Tropfen einer Schwefelammoniumlösung $1: 10$ hinzugefügt, dann $1,5 \mathrm{ccm}$ abgenommen und verimpft auf $8 \mathrm{ccm} \mathrm{Agar.} \mathrm{Die} \mathrm{Cnltur} \mathrm{bleibt} \mathrm{steril.} \mathrm{Dann} \mathrm{werden} 10 \mathrm{ccm}$ dieser Sporensuspension mit $10 \mathrm{ccm}$ Sublimat 1:500 gemischt, nach 2 Stunden das Sublimat durch 5 Tropfen einer Schwefelammoniumlösung $1: 10$ niedergeschlagen, und nun auf die Cultur geimpft $1,5 \mathrm{ccm}$ und einem jungen Kaninchen injicirt etwa 2 bis $3 \mathrm{ccm}$; das Kaninchen starb am 2weiten Tage an Milzbrand. Auf der Cultur wuchsen nur 3 Colonieen. Nach 4 Tagen wird mit derselben Suspension derselbe Versuch gemacht, nur wurde auch noch einer Maus etwa $1 \mathrm{ccm}$ nach Ansäuerung injicirt. $\mathrm{Ka}$ ninchen und Maus starben an Milzbrand in 2 bis 3 Tagen. Die Cultur ging durch einen Zufall verloren.

Also um zu resümiren: Ich habe nie beobachtet, dass ich durch Cultur bei der angewandten Anordnung Keime nachweisen konnte, die nicht infectiös gewesen wären. ${ }^{1}$ )

Behring nun steht in der ganzen Frage auf einem ganz andern Standpunkte. Er sagt: Bei jeder Bacterie kommt, ehe sie abstirbt, ein Stadium vor, in welchem sie noch auf Cultur wächst, aber nicht mehr inficirt. Daher ist unter allen Umständen die Cultur das feinere Reagens auf Anwesenheit von Bacterien. Eine allgemeine Begründung, wie sie doch wohl dieser Satz sehr nöthig gehabt hätte, ist nicht hinzugefügt, sonder'll Behring sagt nur, er könne nachweisen, dass Milzbrandsporen bei Desinfection durch Sublimat (und Ausfällung des Sublimats mit Schwefelammonium) sehr viel länger ihre Keimfähigkeit auf Culturen bewahrten, als ihre Infectionsfähigkeit. Da nun scheinhar dieses Verfahren dasselbe ist, wie ich es angewandt, ich aber zu ganz anderen Ergebnissen gekommen war, so habe ich die Frage noch einer weiteren Prüfung unterzogen.

1) Damit ist natürlich nicht behauptet, dass etwas derartiges nicht vorkommen könne. Es ist wohl möglich, dass, wenn man z. B. die Art, wie man das Quecksilber entfernt, veränderte, man länger Culturen wie Infectionen bekommt. Es lässt sich nämlich nachweisen, dass das Schwefelammonium in grösseren Dosen, als ich es anwandte, in der 'That nachweislich entwickelungshemmessde Eigenschaften hat. Zwei Tropfen der concentrirten Schwefelammoniumlösung vermögın (zugesetzt zu $8 \mathrm{ccm}$ Agar) normalen Milzbrand am Auskeimen zu hindern, ein Tropfen vermag das gleiche bei Sporen, die $3 / 4$ Stunden in Sublimat gelegen hatten: unter diesen Umständen ist es wohl möglich (denn die Empfindlichkeit der vergifteten Sporen gegen Verunreinigungen des Nährbodens steigt mit der Dauer der Desinfection), dass, wenn das Quecksilber auf anderem Wege weggeschafft, oder das Schwefelammonium entfernt würde, auch die Culturergebnisse noch andere sein würden. Indess hat diese Frage mit den lier bchandelten nur einen sehr lockeren Zusammen. litug; daher muss ich sie für eine eigene Untersuchung aufspillen. 
Behring also sagt (p. 443 oben': „Aus den später zu crwähnenden Versuchen geht mit Sicherheit hervor, dass man nach der Sublimatbehandlung der Sporen noch Culturen bekommt, wenn die geimpften Thiere ganz gesund bleiben"... und ferner p. 443 unten: "Bei den hier ausgeführten Versuchen wurden aus Sporenfäden, die nach "3-bis 4 stündiger Einwirkung von 1\% Sublimat mit Schwefelammonlösung 1:3 behandelt waren, in der Regel noch Culturen erbalten, während Thiere nio mehr starben, wenn sie mit Sporenfaden geimpft wurden, die $1^{1 / 2}$ Stunde in $1 \%$ Sublimat gelegen hatten und danach mit Schwefelammon behandelt wurden“. Die Tabelle endlich, welche die genannten Versuche enthält, ist folgende (p. 446): die angelegten Culturen (3. senkrechte Reihe) waren Bouillonculturen.

\begin{tabular}{|c|c|c|c|}
\hline Jösung & $\begin{array}{l}\text { Art der Entfernung } \\
\text { des Desinfections- } \\
\text { mittels }\end{array}$ & $\begin{array}{l}\text { Dauer der Einwir- } \\
\text { kung bis zum Eintritt } \\
\text { der Desinfection -- }\end{array}$ & Bemerkungen \\
\hline $\mathrm{Hg} \mathrm{Cl}_{2} 1: 1000$ & $\begin{array}{c}\text { Wiederholtes } \mathrm{Ab} \text { - } \\
\text { spülen mit warmem } \\
\text { Wasser }\end{array}$ & 30 Minuten -1 ) & \multirow{5}{*}{$\begin{array}{l}\text { Maus stirbt an } \\
\text { Milzbrand } \\
\\
\text { geimpfte } \\
\text { Mäuse bleiber } \\
\text { am Leben }\end{array}$} \\
\hline $\mathrm{Hg} \mathrm{Cl}_{\varepsilon} 1: 1000$ & $\begin{array}{c}\text { Abspülen in }\left(\mathrm{NH}_{4}\right)_{2} \mathrm{~S} \\
\text { dann in Wasser } \\
\text { desgl. }\end{array}$ & $\begin{array}{c}\text { nach } 4 \text { Stunden } \\
\text { noch keine Ab- } \\
\text { tödtung. } \\
3 \text { Stunden - }\end{array}$ & \\
\hline $\begin{array}{l}\text { mit } \mathrm{HCl} \\
\mathrm{Hg} \mathrm{Cl}=1000 \\
\text { mit Weinsäure }\end{array}$ & desgl. & 3 Stunden - & \\
\hline $\begin{array}{c}\mathrm{Hg} \mathrm{Cl}_{2} 1: 100 \\
\mathrm{Hg} \mathrm{Cl} 21: 1000 \\
\text { bei } 37,5^{0} \mathrm{C}\end{array}$ & $\begin{array}{l}\text { desgl. } \\
\text { desg!. }\end{array}$ & $\begin{array}{l}20 \text { Minuten - } \\
3 \text { Stunden - }\end{array}$ & \\
\hline $\begin{array}{l}\mathrm{Hg} \mathrm{Cl}_{2} 1: 1000 \\
\text { mit Weinsäure }\end{array}$ & desgl. & 3 Stunden - & \\
\hline
\end{tabular}

Ausserdem befindet sich noch auf p. 447 eine Tabelle, nach der auch noch nach 10 stündiger Sublimateinwirkung Culturen erzielt seien. Aber Thierversuche enthält diese Tabelle nicht.

Uebersieht man das mitgetheilte Material, so sieht man sofort, dass aus diesem sich die Schlüsse Behring's nicht ziehen lassen. Es ist überhaupt kein Versuch bei $1 \frac{1}{2}$ Stunden angeführt, und nur in einer einzigen Reihe ist es vorgekammen, dass (bei 4 stündiger Einwirkung) sich noch Cultur entwickelte, und das Thierexperiment negativ ausfiel. Bei einer Desinfectionsdauer von drei Stunden ist constant weder Thierinfection noch Cultur aufgetreten. Demnach ist das Hauptmaterial, auf das Behring seine Schlüsse baut, nicht publicirt worden. Warum nicht, dafür finde ich keine Andeutung in der Arbeit. Nun wird sich aber aus dem folgenden ergeben, dass gerade diese Frage sich nur unter ganz sorgfältiger Erwägung aller in Betracht kommenden Umstände entscheiden lässt, und dass sie infolge dessen auch durch ganz genaue Protokolle belegt werden muss. Es blieb unter diesen Umständen nichts übrig, als so genau wie möglich die Frage noch einmal zu untersuchen, und dabei auch die Behring'schen nicht mitgetheilten Versuche, soweit es seine Angaben gestatteten, nachzumachen.

Behring also sagt: nach $1 \frac{1}{2}$ Stunden bekommt man nie mehr Thierinfection, wohl aber stets Cultur, demnach sind die Sporen zu dieser Zeit der Desinfection abgeschwächt. Sein Thatbestand ist, dass Seidenfäden, die $1 \frac{1 / 2}{2}$ Stunden in Sublimat $1: 1000$ und dann 5 Minuten in Schwefelammon 1:3 gelegen hatten, nicht mehr inficirten, wohl aber Culturen lieferten. Hier erhebt sich sofort die Frage, die Behring nicht einmal aufwirft: Sind nicht vielleicht bei diesem Versuch andere Momente vorhanden, die die Infection hindern? Ist mit einem Wort das Ausbleiben der Infection nothwendig auf eine Abschwächung zu beziehen?

Dass ein derartiges accessorisches Moment hier im Spiel sei, wurde sofort klar, als ich an's Experimentiren ging. Die erste Frage, die ich mir vorlegte, war, ob es denn nie, resp. sehr selten vorkäme, dass Sporen eine Sublimateinwirkung von $1^{1 / 2}$ Stunden überdauern, ohne ihre Infectiosität zu verlieren. Ich nahm eine Anzahl von Agarculturen, die etwa 4 Tage alt waren (denn Behring nahm das gleiche Material), fertigte Suspensionen aus ihnen an, filtrirte sie und untersuchte dann in der angedeuteten Richtung. Vier dieser Reihen sind bereits mitgetheilt; in allen erwiesen sich die Sporen noch nach $1^{1} / 2$ Stunden für Meerschweinchen resp. Mäuse, einmal sogar noch nach 2 Stunden für Kaninchen giftig. Ich habe dann noch 4 weitere Versuche angestellt.

Reihe 5. $30 \mathrm{ccm}$ Sporensuspension und $30 \mathrm{ccm}$ Sublimat 1:500 werden gemischt, nach $1 \frac{1}{2}$ Stunden mit einigen Tropfen conc. Schwefelammoniumlösung niedergeschlagen. Auf Agar wird $1 \mathrm{ccm}$ auf ein Meerschweinchen etwa $3 \mathrm{ccm}$ verimpft. Auf der Cultur etwa 30 Colonieen, das Meerschweinchen stirbt an Milzbrand.

1) Nach den Ergebuissen dieser Reihe, unter Berücksichtigung des Kopfes der Tabelle, wäre also nach 30 Minuten der Sporenfaden desinficirt gewesen, da er in Bouillon nicht mehr auswuchs. Der Controllfaden aber inficirte noch. Demnach wäre ein Gegenstand dann als desinficirt anzusehen, wenn er keine Cultur mehr liefert, selbst wenn er noch ein Thier inficiren kann.
Reihe 6. Anordnung, wie beim vorigen Versuche. Aber die Cultur bleibt steril, und das Meerschweinchen gesund.

Reihe 7. $3 \mathrm{ccm}$ Sporensuspension und $7 \mathrm{ccm}$ Wasser werden mit $10 \mathrm{ccm}$ Sublimat $1: 500$ gemischt und nach $1 \frac{1}{1} / 2$ Stunden durch 3 Tropfen conc. Sehwefelammoniumlösung niedergeschlagen. Impfung, wie beim vorigen Versuch; Cultur steril, Meerschweinchen bleibt leben.

Reihe 8. $10 \mathrm{ccm}$ Sporensuspension und $10 \mathrm{ccm}$ Sublimat 1:500 werden gemischt, nach $1 \frac{1}{2}$ Stunden durch 3 Tropfen conc. Schwefelammonlösung niedergeschlagen. Weitere Anordnung wie bei den vorigen Versuchen. Meerschweinchen stirbt am 3. Tage an Milzbrand, und auf der Cultur etwa 40 Colonieen.

Reihe 2. Fortsetzung. Bei dieser Reihe habe ich mich durch Kochprobe überzengt, dass ich nicht etwa sehr widerstandsfähige Sporen benutz hatte. Ich that $5 \mathrm{ccm}$ der filtrirten Suspension in einen kleinen Porcellantiegel von $25 \mathrm{ccm}$ Inhalt und schob dann einen starken Bunsenbrenner darunter. Nach 10 Secunden stiegen die ersten Blasen, nach 20 Secunden trat heftiges Sieden ein. Das Sieden erhielt ich in mässigem Grade durch passende Regulirung der Flamme. Dann goss ich nach bestimmter Zeit $10 \mathrm{ccm}$ kalten sterilisirten Wassers hinzu, wodurch die Temperatur sofort auf $50 \mathrm{Grad}$ sank. Dann wurden auf Agar etwa $1 \frac{112}{\mathrm{ccm}}$ abgeimpft. Dieses Verfahren wurde mit derselben Suspension mehrere mal wiederholt Nach $1 / 2$ Minute (gerechnet vom Moment, wo die Flamme untergeschoben wird) traten etwa 60 Colonieen auf, nach 1 Minute 12 Colonieen, nach $1^{1 / 2}$ Minuten nichts mehr, ebenso wenig nach 2 Minuten und 3 Minuten.

Dann wurden Seidenfäden $(0,3 \mathrm{~mm}$ stark $)$, die in dieser Suspension gelegen hatten und einige Stunden getrocknet waren, geprüft. Wieder wurden je $5 \mathrm{ccm}$ Wasser in den Porcellantiegel gethan, aber nun mit der Flamme zuerst zum Sieden erhitzt, und dann je 2 Fäden in das kochende Wasser geworfen, dann $10 \mathrm{ccm}$ Wasser hinzugefügt und nun die Fäden in Bouillon gebracht. Nach $1 / 2$ Minute langem Sieden trat in beiden Fäden Entwickelung auf, ebenso nach 1 Minute langem; jedoch beim einen Faden crst am 2. Tage. Nach $1^{1 / 2}$ etc. Minuten trat keine Entwickelung mehr auf.

Ferner wurden $10 \mathrm{ccm}$ dieser Suspension mit $10 \mathrm{ccm}$ Sublimat 1:500 gemischt, dann nach $2^{1 / 2}$ Stunden durch einige Tropfen Schwefelammonium niedergeschlagen, und $1 \mathrm{ccm}$ auf Cultur gebracht; es wuchs nichts. (Nach $1^{1 / 2}$ Stunden (s. oben) war Cultur und Infection erfolgt).

Diese Versuche ergeben: Unter 8 untersuchten Culturen waren 6 noch nach $1^{1 / 2}$ stündiger Sublimateinwirkung infectiös. In einer Reihe (Reihe 2 Forts.) war speciell geprüft, ob ich etwa besonder widerstandsfähige Sporen verwandt hätte. Das war nicht der Fall Nach 11/2 Min. langem Kochen, sowie nach 21/2 stündiger Sublimateinwirkung keimten sie nicht mehr aus, während ich sonst noch Auskeimen nach 6 Minuten langem Kochen, resp. 24 stündiger Sublimatwirkung gesehen hatte.

Da ich nun doch nicht annehmen konnte, dass Behring mit ganz aussergewöhnlich wenig widerstandsfähigen Sporen gearbeitet habe, denn er selbst hebi (p. 441 Mitte) hervor, dass die im hy gienischen Institut jetzt gezüchteten Sporen von besonderer Resistenz seien, so ging schon aus diesen Versuchen als sehr wahrscheinlich hervor, dass Behring's Methode die Schuld an seinen ganz anders ausgefallenen Resultaten trage. Dieser Schluss wird dann noch durch Folgendes unterstützt: In einer filtrirten Suspension, wie ich sie benutze, schwimmt jede Spore wirklich im Sublimat, sie steht also von Anfang an unter seiner vollen Wirkung Anders ist es am Faden, den Behring brauchte. Nimmt man Seidenfäden (die meinigen, die ich zu diesem Versuch benutzte, hatten eine Dicke von $0,5 \mathrm{~mm}$ ), wirft sie in Sublimat $1: 1000$, und dann nach einiger Zeit in eine Schwefelammonlösung $1: 3(\mathrm{~B} \mathrm{eh}$. ring's Methode), so färbt sich durch das niedergeschlagene Schwefelquecksilber der Faden braunschwarz. Bringt man nun nach etwa 5 Minuten den Faden in Wasser und zerzupft ihn dort, so sieht man sofort, dass jetzt die drei Fädchen, aus denen zunächst der Faden niedergesponnen ist, abwechselnd schwarz und weiss aussehen. An den Stellen, wo das Fädchen den Sublimat exponirt war, ist es schwarz, an den Stellen, wo es durch ein darüber liegendes anderes Fädchen geschützt war, ist es weiss, resp. hell Man kann diese Erscheinung noch nach einer halben Stunde nachweisen. Legt man die Fädchen zurück in die Schwefelammonlösung, so fărben sich die lichten Partieen nicht dunkler. Die Erklärung ist sehr einfach: Das Sublimat dringt (genau wie das Chlor) langsam in den Faden ein. Die Stellen, wo ein Fädchen das andere bedeckt, werden später durchtränkt, als die, wo es freiliegt. Demnach kommen eine Anzahl Sporen sehr vie später unter die Einwirkung des Sublimats; demnach müssten am Faden sich die infectiösen Eigenschaften der Sporen länger erhalten, als in der Suspension.

Zunächst unternahm ich nun gewissermaassen ein Tastexperiment. Ich nahm 4 Fäden von 4 verschiedenen Culturen, legte sie $\mathbf{1}^{1 / 2}$ Stunde in $1 \%$ iges Sublimat, und dann in Schwefelammonium 1:3. Und zwar blieben zwei davon 5 Minuten in dieser Lösung, einer eine Stunde, einer 24 Stunden. Dann wurden sie auf Mäuse verimpft. Die drei ersten Mäuse erkrankten nicht, dagegen die vierte, deren Faden 24 Stunden im Schwefelammonium gelegen hatte, starb am dritten Tage an Milzbrand. Das Ergebniss war auffallend; denn es konnte ja sein, dass ich an dem einen infectiösen Faden gerade sehr widerstandsfähige Sporen hatte, aber auf der 
anderen Seite war er auch der einzige, der 24 Stunden im Schwefelammonium gelegen hatte. Dieser Versuch begründete also den Verdacht, ob denn das Sublimat im Faden bei der Methode Behring's (der nur 5 Minuten im Schwefelammonium liegen lässt) wirklich gänzlich ausgefällt sei. Dass es nicht ganz leicht sei, das Sublimat auszufällen, hatte ich bereits früher bewiesen, denn bei Anwendung verdünnter Schwefelammonlösung war es mir nicht gelungen, aus den Fäden eine Cultur zu gewinnen. Ich hatte auch sofort den Grund dazu angegeben: Der entstehende Niederschlag sehützt das Innere des Fadens vor dem weiteren Eindringen der Schwefelammoniumlösung. Mit sehr viel concentrirteren Lösungen, wie sie Behring braucht, war es offenbar möglich einzudriugen in den Faden. ${ }^{1}$ )

Eines allerdings schien diese Anschauung direkt zu widerlegen: Behring hatte aus seinen Fäden Culturen gezogen. Das war nicht möglich, wenn noch Sublimat an den Fäden haftete. Ich habe daher so genau, wie es Behring's Angaben zulassen, seine Versuche nachgemacht. Ich bereitete mir Fäden genau nach Behring's Anweisung (p. 439), indem ich sterilisirte Seidenfäden²) in eine Sporensuspension legte, und sie dann nach gehöriger Durchtränkung (ich liess sie mehrere Stunden in der Suspension) in ein anderes Schälchen zum Trocknen brachte.

In Bezug nun auf dieses Material sagt Behring: "Sporen von grosser und gleicher Widerstandsfăhigkeit . . . bekommt man von Culturen auf schräger Agarfläche in Reagensgläsern, die im Brütschrank noch drei Tage nach Beginn der ersten Sporenbildung gehalten werden." Einen Beweis dafür, dass diese Sporen ein gleiches Widerstandsvermögen haben, hat Behring nicht erbracht. Er versichert es nur. Dagegen hatte ich nachgewiesen, dass gegen jedweden Einfluss die verschiedenen Sporen einer solchen Cultur sich ausserordentlich verschieden verhalten. Die eine Spore verliert nach einer halben Minute im-kochenden Wasser die Fähigkeit, in Agar auszukeimen, die andere erst nach $1^{1 / 2}$ Minuten. Ich habe Differenzen von $1 / 2$ bis 6 Minuten in derselben Cultur beobachtet. Ebenso ist es bei Einwirkung von Sublimat oder anderen Desinfectionsmitteln.

Ich hatte zur Herstellung der Fäden zunächst die Suspension von Reihe 2 vor der Filtration benutzt. ${ }^{3}$ ) Sie stellte auch schon vor der Filtration eine ziemlich homogene Flüssigkeit dar. Die Fäden wurden nach Behring's Anweisung so aufbewahrt, dass nicht bloss die Einwirkung des direkten Sonnenlichtes, sondern auch des diffusen Tageslichtes ausgeschlossen war". Sie waren $0,3 \mathrm{~mm}$ stark.

Ich hatte nun von vornherein einen gewissen Argwohn, ob wohl diese Fäden ein wirklich gleichmässiges Material darstellten. Ich untersuchte dies durch Desinfection in siedenden Wasser in der Weise, wie es oben (Fortsetzung von Versuch 2 nach Versuch 8) geschildert ist. Am vierten, siebenten und dreissigsten Tage, nachdem die Fäden angefertigt waren, wurden je drei Fäden (der oben erwähnte Versuch ist hier nicht mitgerechnet, er wurde am ersten Tage angestellt) eine Minute lang gekocht. Von diesen 9 Fäden entwickelten sich zwei überhaupt nicht (vom vierten und siebenten Tage je einer4), an den übrigen war das Wachsthum ausserordentlich verschieden. Bald entwickelte sich erst am zweiten Tage die Cultur, bald am ersten. Einmal sprosste die Cultur aus dem grössten Theil des Fadens, ein anderes mal war sie auf eine Stelle beschränkt. Also ein wirklich gleichmässiges Material hatte ich nicht vor mir. Das war sehr unangenehm, denn wenn ich einigermaassen sicher gehen wollte, so musste ich von nun an für jeden einzelnen Versuch doch auch mehrere Fäden ansetzen, um wenigstens einiger-

l) Behring sagt: „Woher es kommt, dass Geppert bei seinen Versuchen mit Sporenfäden "nicht zu einem befriedigenden Resultat gelaugte, ist mir nicht reeht erklärlich"'. Die oben gegebene Erklärung liegt wohl ziemlich nahe. Ausserdem hatte ich ein anderes Culturverfahren. Doch muss ich eins zu dieser Bemerkung Behring's hinzufügen: Mir kam es bei diesen Versuchen am Faden vor allem darauf an, chemisch nachzuweisen, dass auch nach sehr sorgfältiger Abspülung mit Wasser noch Sublimat am Faden hafte; und der Nachweis gelang sofort. Dagegen war mir die Frage, ob es gelinge, das Quecksilber gănzlich im Faden niederzuschlagen, und so die Sporen frei zu machen, sehr gleichgiltig. Ich hatte nachgewiesen, dass Sporen, die isolirt im Sublimat stundenlang schwammen, nicht abgetödtet waren, ich hatte nachgewiesen, dass sie am Seidenfaden sich nicht entwickeln können, weil Sublimat an ihm haftet, - da hatte es kein Interesse mehr, zuzusehen, wie man bei dieser speciellen Versuchsanordnung dasselbe nachweisen könne, was überzeugend mit sehr viel vorwurfsfreierer Methodik dargethan war.

2) Behring sagt, seine Fäden hätten mittlere Dicke gehabt und seien stärker gewesen als die von Nocht gebrauchten. Wie dick aber seine resp. die von Nocht gebrauchten gewesen seien, sagt er nicht. Da man unter Seidenfäden von mittlerer Dicke solche von 0,3 bis $0,5 \mathrm{~mm}$ Durchmesser zu verstehen pflegt, habe ich Seidenfãden dieser Stärke benutzt. Es ist jedes mal angegeben, wie stark die benutzten Seidenfäden waren.

${ }^{3}$ ) Behring giebt nicht an, dass er seine Suspensionen filtrirt habe, ehe er die Fäden hinein legte, daher habe ich es auch nicht gethan.

4) Am vierten Tage war es der zuerst aus dem Porcellantiegel genommene, am siebenten der zuletzt heraus genommene. maassen mich vor diesen Ungleichheiten zu schützen und einen Durchschnittswerth zu bekommen.

Als ich nun an die Sublimatversuche ging, erhob sich eine neue Schwierigkeit. Behring sagt im Text (p. 443 und 445), dass die Fäden, nachdem sie in Sublimat und dann 5 Minuten in Schwefelammonium 1:3 gelegen hätten, auf Bouillonröhrchen gethan wären. In der erwähnten Tabelle (p. 446) steht: Die Fäden seien nach der Einwirkung des Schwefelammoniums in W a sser und dann in Bouillon gethan. Nach dieser Stelle wären sie also erst in Wasser gekommen, nach der anderen nicht. Es mag vielleicht pedantisch erscheinen, auf eine solche Kleinigkeit Werth zu legen, aber es hat sich gezeigt, dass sie von grosser Bedeutung ist. Jedenfalls weiss man nun nicht, wie das bei den nicht publicirten Versuchen gehalten wurde.

Zuerst also legte ich (am siebenten Tage, nachdem die Fäden angefertigt waren) 4 Fäden in Sublimat $1: 10001^{1 / 2}$ Stunde lang, dann 5 Minuten in Schwefelammonium 1:3 und impfte sie dann direkt auf drei Bouillonröhrchen, sowie auf eine Maus. Die Maus starb am vierten Tage an Milzbrand, die Fäden in den drei Röhrchen wuchsen aus, und zwar zwei ziemlich stark, eins nur zur Hälfte. Zunächst sah ich hier, dass das nie" das Behring ausgesprochen, sich nicht bestätigen liess. Dies war die zweite Infection vom Seidenfaden nach $1^{1 / 2}$ stündiger Sublimat einwirkung, und dazu waren die Sporen keineswegs abnorm widerstandsfähig (siehe die Zahlen oben). Am Tage, nachdem dies Experiment angesetzt war, wurde ein zweites begonnen. 3 Fäden wurden in Sublimat 1:1000 gelegt, dann in Schwefelammonium $1: 3$, dann aber 5 Minuten in Wasser, und nun wurden 2 Fäden in Bouillon gethan und einer auf eine Maus verimpft. Der Erfolg war: Aus keinem Faden entwickelte sich eine Cultur, und die Maus blieb gesund. Für den krassen Gegensatz dieser beiden Reihen gab es nur eine Erklärung: Die Zeit, welche die Fäden im Schwefelammonium zugebracht hatten, hatte nicht ausgereicht, das Sublimat in ihnen auszufällen; blieb nun Schwefelammonium an ihnen hängen (wie im ersten Versuch), so hatte es Zeit, nachzuwirken, und fällte das Sublimat aus, die Sporen wurden frei. Wurde es aber abgespült im Wasser, so fiel diese Nachwirkung natürlich aus. War die Erklärung richtig, dann musste es (im Gegensatz zum Sublimat) relativ leicht sein, Schwefelammonium vom Faden zu entfernen. Das ist nun in der That der Fall. Legt man Seidenfäden in Schwefelammoniumlösung 1:3 5 Minuten lang ein, bringt sie dann in Wasser und von da in eine Sublimatlösung, so sieht man, dass nach 3-4 Minuten dauernder Waschung in Wasser kaum noch eine Spur Schwefelammonium nachweisbar ist. Nun können sich allerdings beim Experiment, wie es Behring gemacht, die Verhältnisse noch etwas anders gestalten. Denn wenn der Faden aus Sublimat in Schwefelammonium kommt, dann umgiebt und durchsetzt er sich mit einem dichten Niederschlag von Schwefelquecksilber. $O b$ es nun immer möglich sein wird, das Schwefelammonium aus diesem heraus zu waschen, das kann man nie vorher sagen. Chemische Niederschläge können Lösungen so ausserordentlich festhalten, dass alles Auswaschen nicht hinreicht. Hier aber ist der Niederschlag noch an und in einem Faden befindlich. Also sieht man von vornherein, dass man hier in eine Fülle von Complicationen gerathen kann, die garnicht übersehbar sind. Ich liess nunmehr die Fåden 3 Wochen im dunkelen Schrank liegen. Bei so langem Liegen lockert sich das Gefüge dieser kurzen Stückchen, sie kräuseln sich auf. Und nun stellte ich mit ihnen eine neue Reihe von Experimenten an, deren Protokolle ich hier folgen lasse.

Es ist zweckmässig, für die Wachsthumsverhältnisse an den Fäden kurze Bezeichnungen einzuführen. Es bedeutet also im Folgenden: 0 Kein Wachsthum. 1 Wachsthum an einer Stelle. 2 Wachsthum über ein Vierte des Fadens. 3 Wachsthum über die Hälfte des Fadens. 4 Wachsthum am ganzen Faden. Die Beobachtungen beziehen sich auf den zweiten Tag nach dem Experiment. Nach dem zweiten Tage habe auch ich bei diesen Versuchen nicht mehr gesehen, dass ein bis dahin steriler Faden ausgewachsen wäre. Behriug giebt dasselbe an. Doch wurden die sterilen Fäden stets noch länger beobachtet. Jeder Faden kam in ein Röhrchen ür sich, das mit Bouillon gefüllt war. Schw. bezeichnet Schwefelammonlösung 1:3. Die Schwefelammonlösung war die oben (Protokoll von Reihe 2) genannte.

Fortsetzung von Reihe 2. Fäden sind 30 Tage alt. Dauer der Desinfection in Sublimat $1: 1000$ in den folgenden Experimenten $1^{1 / 2}$ Stunde. 6 Făden aus Sublimat in Schw. 5 Minuten lang. 3 Fāden direkt in Bouillon: 044. 3 Fäden mit Wasser abgespült: 240 .

Im folgenden Experiment werden die Fäden, die nach der Schwefelammoniumbehandlung in Wasser gelegt werden, in lauwarmes Wasser $1 / 2$ Stunde gebracht, und dann noch einmal mit Wasser abgespült. Fäden 32 Tage alt.

3 Fäden 3-4 Minuten in Schw.: 444. 3 Fäden 2-3 Minuten in Schw. dann in Wasser: 140. 3 Fäden 6 Minuten in Schw. 434. 3 Fāden 6 Minuten in Schw. dann in Wasser: 031. 3 Fäden ${ }^{3 / 4}$ Stunde in Schw. 040. 3 Făden $3 / 4$ Stunde in Schw. dann in Wasser: 403 .

Desinfection $2 \frac{1}{2}$ Stunde in Subl. 1:1000. Fäden 7 Minuten in Schw. 443. Ebenso aber vorher in Wasser: 303 . 
Fäden 39 Tage alt. Desinfection durch Subl. 1:1000, 2\% Stunde lang. Dann Schw. 5 Minuten lang 444. Ferner ein kleines Meerschweinchen mit 2 Fäden geimpft; stirbt nach 4 Tagen, aber nicht an Milzbrand. Die Fäden sind vereitert. 2 Fäden bleiben in Schwefelammon 1:20 durch 24 Stunden, werden dann auf eine Maus geimpft. Sie bleibt gesund, aber nach 6 Tagen zeigt sich, bei Oeffnung der Stelle, wo die Fäden liegen, dass sie vereitert sind. Eine Maus wird geimpft mit einem Faden, der 4 Stunden in Schw. gelegen hatte. Stirbt nach 6 Tagen. Im Blut keine Stäbchen, ebensowenig in der Milz. Aber an der Impfstelle ein sehr starkes 0edem vom Aussehen des Milzbrandödems. Im Oedem eine grosse Anzahl Coccen und eine geringe Anzahl Stäbchen vom Aussehen der Milzbrandstäbchen, aber blass gefärbt.

Reihe 9. 6 Fäden (Dicke 0,6 mm) 5 Tage alt, aus einer anderen Sus pension, werden 11/2 Stunde in Sublimat 1:1000, dann 5 Minuten in Schw. gelegt. 3 werden direkt auf Bouillon verimpft: 444 . 3 Fäden vorher $5 \mathrm{Mi}$ nuten in warmes Wasser 220 .

Reihe 4. Fortsetzung. In die Suspension von Reihe 4 (s. oben) werden vor der Filtration Seidenfäden $(0,3 \mathrm{~mm}$ stark) gelegt, nach einigen Stunden herausgenommen und in desinficirte Schalen gelegt. Die Prüfung der filtrirten Suspension (s. oben) hatte ergeben, dass nach 2 stündiger Einwirkung von Sublimat 1:1000 nur sehr wenige Keime noch durch Cultur nachweisbar waren. Und doch war die Suspension noch für Kaninchen und Mäuse infectiös. Die Suspension sab bereits vor der Filtration sehr gleichmässig aus, hatte kaum mit blossem Auge erkennbare körperliche Bestandtheile.

Fäden 4 Tage alt. Desinfection in Sublimat 1:1000 1/2 Stunde, dann Schw 5 Minuten. 3 Fäden direkt in Bouillon: 444. 3 Fäden vorher 10 Minuten in lauwarmes Wasser: 100

3 Fäden 4 Stunden in ein Schälchen mit Wasser: $443^{1}$ ) -3 Fäden ebenso behandelt, wie die letzten, aber aus dem Wasser noch einmal $1 \mathrm{Mi}$ nute in Sch. 044 .

Geimpft werden 1) eine Maus mit 2 Fäden, die 5 Minuten in Schw. gelegen hatten; 2) eine Maus mit 2 Fäden, die 5 Minuten in Schw. und dann 4 Stunden in Wasser gelegen hatten. Beide bleiben gesund. Aber als nach 7 Tagen die Stelle, wo die Fäden liegen, aufgeschnitten wird, liegen die Fäden im Eiter.

Aus dem mitgetheilten Material kann man sich ein ziemlich genaues Bild dessen machen, was bei einer solchen Versuchsanordnung vorkommen kann.

Zunächst sieht man sofort, dass auch in diesen Versuchen die Abspülung mit Wasser nach der Schwefelammoniumbehandlung den Erfolg hat, dass jetzt das Wachsthum dieser Fäden weit hinter dem der nicht mit Wasser abgespülten zurückbleibt. So deutlich wie bei den ersten Versuchen war das Phänomen bei den älteren Fäden nicht. Ich vermuthe, dass die Aufkräuselung der Fäden die Schuld hat. Jetzt kann das Schwefelammonium leichter eindringen, und vielleicht wird es nun auch in dem massenhafteren Quecksilberniederschlag fester gehalten, denn in den aufgelockerten Fäden ist mehr Sublimat angesammelt. Mit frisch präparirten Fäden (Reihe 4 Fortsetzung) trat die Erscheinung sofort wieder deutlich auf. Das schlimmste aber ist, dass bei diesen Fäden, die mit Wasser behandelt sind, die allergrössten Ungleichheiten zu verzeichnen sind. Von ganz gleich behandelten Fäden wächst aus dem einen eine Cultur, aus dem andern nicht. Ich möchte dies betonen, denn die einzige von Behring mitgetheilte Reihe ist mit solchem Material unternommen.

Während also noch nach $2 \frac{1}{2}$ stündiger Desinfection an mehreren Fäden, die direkt aus dem Schwefelammonium in Bouillon gelegt wurden, die Culturen kräftig wuchsen, kamen bei diesen, die nur $1^{1 / 2}$ Stunde desinficirt waren, doch eine Reihe von Fällen vor, bei welchen keine Cultur erzielt wurde. Daran sind vermuthlich die Fäden schuld. Der eine Faden rollt sich mehr auf, der andere weniger. Einmal allerdings ist es auch vorgekommen, dass ein Faden, der direkt aus dem Schwefelammonium in Bouillon gelegt wurde, auch keine Cultur zeigte. Also ganz sicher ist man hier seines Materials auch nicht. Um also das Resultat zusammenzufassen: Binnen 5 Minuten ist selbst mit der angewandten relativ concentrirten Schwefelammoniumlösung eine sichere Ausfällung des Sublimats im Faden nicht garantirt.

Weitere Beweise nun, dass bei den Behring'schen Versuchen Nebenumstände mitgewirkt haben können, enthält die eben mitgegetheilte Fortsetzung von Reihe 4. Nach 2 stündiger Desinfection durch Sublimat 1:1000 waren in einem halben Cubikcentimeter der filtrirten Suspension nur noch drei Keime durch Cultur nachweisbar. Und doch war ungefähr die gleiche Menge noch für Kaninchen und Mäuse infectiös. ${ }^{2}$ ) Andere Resultate ergaben die Fäden, die mit dieser Suspension imprägnirt waren.

Aus ihnen wuchs nach $1 \frac{1}{2}$ stündiger Sublimatbehandlung eine üppige Cultur; jedoch sie inficirten nicht mehr. Der Gegensatz war ausserordentlich auffallend. Eine nähere Untersuchung zeigte nun, dass hier noch ein Moment im Spiele war, an das ich allerdings auch nicht gedacht hatte. Es war mir schon auf-

1) Bei diesem Experiment war der Vorgang folgender: Die Fäden kamen aus Schw. in ein Schälchen mit etwa $15 \mathrm{ccm}$ Wasser und blieben darin. Dabei entsteht im Wasser eine dünne Schwefelammoniumlösung, die vermuthlich in den 4 Stunden das Sublimat ausfällte.

2) In einem halben Cubikcentimeter einer solcher Suspension sind von Anfang an tausende von Keimen. gefallen, dass bei den zuerst mitgetheilten Versuchen einige Thiere (ein Meerschweinchen und eine Maus, s. oben) gestorben waren, aber nicht an Milzbrand. An der Wunde hatte sich einmal eine Eiterung gefunden, und einmal eine Affection, die so aussah, wie ein Milzbrandoedem, in das eine Cocceninvasion eingedrungen war. Derartiges ist mir sonst ausserordentlich selten, und bei Einlegung von Milzbrandfäden, ich kann wohl sagen, nie passirt. Dass die Fäden an sich nichts fremdes enthielten, dafür spricht, dass in den Culturen sich nie fremde Beimengungen zeigten. Die Instrumente zur Impfung waren dicht vor dem Gebrauche geglüht und in siedendem Wasser abgelöscht. Also ich glaube nicht, dass diese Invasion fremder Coccen durch meine Schuld gekommen war. Es musste etwas in der Anordnung der Experimente liegen, was die Secundärinfectionen begünstigte. Man braucht nicht sehr weit zu suchen, um .das Moment zu finden. Ein mit Niederschlag durchsetzter Faden von×1 cm Länge, der am Ende eines Wundcanals liegt, der mit der äusseren Haut communicirt, ist an sich ein mechanisch reizender Gegenstand. Ist er aber noch mit Schwefelammonium beladen, so wird er die Umgebung intensiv reizen. Dann sind die Bedingungen für einen Wundschluss sehr ungünstig, und die Wege für die Invasion von aussen stelien offen. Denn bei einem Thier die äussere Wundöffnung aseptisch zu halten, ist, soweit mir bekannt, bei diesen Experimenten nie versucht. Daraufhin untersuchte ich dann etwa 7 Tage nach der Impfung bei den übriggebliebenen Mäusen die Impfstelle. Von aussen zeigte sich nichts auffallendes. Die schwarzen Fäden schimmerten durch die Haut, und die kleine Wunde war verklebt. Als ich aber die Haut durchschnitt, zeigte sich bei allen, dass die Fäden im Eiter lagen. Unter diesen Umständen ist es nicht wunderbar, dass diese Sporen nicht inficiren konnten. In diesem Nährboden konnten sie nicht gedeihen. Wenn ich nun auch zugeben will, dass vielleicht äussere Umstände bei diesen Resultaten mitgewirkt haben mögen, so wird man doch andererseits zugeben müssen, dass, wer aus dem Ausbleiben der Infection auf eine Abschwächung der Sporen schliessen will, nachweisen muss, dass derartige Zwischenfälle an der Wunde nicht stattgefunden haben. Von solchen Möglichkeiten aber erwähnt Behring nichts.

Also, wenn ich resümire, ergiebt sich: Wenn Behring sagt, dass er nach $1^{1 / 2}$ stündiger Desinfection der Fäden durch Sublimat 1: 1000 nie eine Infection gesehen habe, so kann ich nur sagen, dass sie vorkommen, ohne durch besondere Resistenz der Sporen erklärbar zu sein.

Das Material, das Behring benutzte, war ungleichwerthig, daher zu vergleichenden Versuchen nicht zu benutzen.

Die Methode, vermittels deren er glaubte, das Sublimat mit „Sicherheit und Leichtigkeit" auszufällen, reicht nachgewiesenermaassen hierzu nicht aus.

Es ist keine Sicherheit gegeben, dass nicht die Vorgänge an der Wunde auch bei Behring's Versuchen die Infection vereitelt haben.

Das auffallende ist, dass, obgleich doch schon sehr schwere Bedenken gegen den Gebrauch von Fäden für einen solchen Zweck wie den vorliegenden, bestanden, Behring doch nie einen Controllversuch mit einer Suspension angestellt hat. ${ }^{1}$ )

Zum Schluss möchte ich noch einen ganz interessanten Punkt hervorheben. Wenn, wie oben nachgewiesen, das Sublimat so langsam in den Faden eindringt, so muss man auch an sich länger aus den Fäden Culturen ziehen können, als aus den filtrirten Suspensionen. Das ist denn in der That auch der Fall. In Reihe 4 liessen sich aus der filtrirten Suspension nach 21/2 stündiger Desinfection keine Culturen mehr ziehen, wohl aber noch aus einer Anzahl von Fäden. Es beweist das wieder einmal, dass die Resultate, die man mit filtrirten Suspensionen bekommt, nicht stimmen und niestimmen können mit dem, was man am Faden erhält, wenigstens, so lange es sich um Desinfection durch chemische Stoffe handelt.

Ich bin nun mit der Besprechung der Kritik Behring's bis auf einen mehr persönlichen Punkt, den ich sofort berïhren werde, am Ende. Behring macht mir zwei Einwürfe: Ich hätte nichts wesentlich neues gefunden, und ich hätte bei meinen Culturen stets Sublimat mit verimpft und dadurch Fehler gemacht. Was es mit den Einwürfen auf sich hat, ist wohl zur Genüge klargestellt. Aber eins muss doch auffallen: Die Chlorversuche, aus denen doch mit Evidenz hervorgeht, dass man am Faden nie richtige Resultate hinsichtlich der Widerstandskraft der Bacterien bekommen kann (denn die Zeit, die man zur Desinfection nöthig hat, richtet sich nach der Dicke der Schicht), sind mit keinem Wort erwähnt.

Der letzte Punkt von Behring's Kritik ist nun folgender. Er sagt:

"Noch eine andere irrthümliche Auffassung Gep pert's muss ich zurückweisen, die auf einer Verwechselung von desinficirender und entwicklungshemmender Wirkung beruht. In verschiedenen meiner Arbeiten habe ich die antiseptische Leistungsfähigkeit des Sublimats in eiweisshaltigen Flüssigkeiten besprochen und dabei erwähnt, dass durch

1) Beim Gebrauch der Suspension, die eingespritzt wird, kann man auch die Secundärinfection mit Sicherheit ausschliessen. 
dasselbe Milzbrandbacillen in ihrer Entwicklung vollständig gehemmt werden, wenn es z. B. im Serum im Verhältniss von 1 : 10000 enthalten ist.

Hierüber sagt Geppert folgendes: .Es sind das Zahlen, die nur für die Cultur Gültigkeit haben, nicht für das Thierexperiment. Nach Behring soll Sublimat in Eiweisslösungen das Wachsthum des Milzbrandes schon bei Zusatz von 1: 10000 hemmen. Versetzt man nun verdïnntes Blut, dem man Sporen beigemengt hat, mit Sublimat 1:1000 und verimpft es, dann stirbt das Thier stets an Milzbrand. Hätte man Wasser statt Sublimat in das Blut gegossen, so wäre der Effect derselbe gewesen. Demnach sieht man, wie ganz anders die Verbăltnisse im Thierkörper liegen, wie in der Cultur, was sehr begreiflich."

Offenbar legt Geppert mir die Meinung bei, ich hătte geglaubt, im Serum durch einen Sublimatgehalt von 1: 10000 die Sporen unschädlich machen zu können, während ich thatsächlich nur behaupte, dass sie dadurch in der Cultur am Auskeimen verhindert werden - ein Unterschied, der denn doch ein ganz gewaltiger ist, und ich muss gestehen, dass mich diese Confundirung von Bacterienentwicklungshemmung und Bacterientôdtung einigermaassen überrascht hat. Bekanntlich ist schon in der Desinfectionsarbeit von R. Koch 1881 der überaus grosse Unterschied zwischen entwicklungshemmender und bacterientödtender Wirkung in erschöpfender Weise besprochen worden, so dass ich hierauf nicht mehr einzugehen brauche."

Nach Behring hätte ich mir also den Unterschied zwischen Entwicklungshemmung und Bacterientödtung nicht klargemacht und infolge dessen beide Begriffe bei Beurtheilung seiner Arbeit confundirt. Die Sache liegt aber anders. Hier sagt Behring, er habe nur behauptet, dass seine Zahlen für die Cultur Gültigkeit hätten, mit anderen Worten also, dass sie auf die Verhältnisse im Thierkörper keine Rückschlüsse gestatteten. Behring hat vergessen, was er selbst geschrieben hat. Ein langer Artikel in dieser Wochenschrift ${ }^{1}$ ) behandelt den einen Gedanken, dass Entwicklungshemmungsversuche im Reagensglas bindende Rückschlüsse auf die Vorgänge in der Wunde, also im Thierkörper gestatteten, falls diese Entwicklungshemmungsversuche mit Blutserum angestellt würden. Er sagt direct:

„Wenn nur die Versuchsanordnung zweckentsprechend gewăhlt wird, dann "liefert die Feststellung des antiseptischen') Werthes im Laboratorium auch für die Praxis durchaus zuverlässige und brauchbare Resultate." Unter Praxis versteht Behring hier die Wundbehandlung.

Weiter sagt er: "Es muss eine der ersten Forderungen sein, dass die Prüfung des antiseptischen Werthes eines Mittels, welches im Innern des menschlichen Körpers Allgemeinwirkungen ausüben, oder in Wunden angewendet werden soll, an solchen Nährböden vorgenommen wird, die eine der Körperflüssigkeit äbnliche Zusammensetzung besitzen; dieser Anforderung entspricht aber von den durchsichtigen Nährböden zweifellos am meisten das Blutserum."

Man kann wohl kaum deutlicher ausdrücken, dass man das Blutserum als Nährboden für die Versuche über Entwicklungshemmung deshalb gewählt hat, weil man glaubte, aus diesen Versuchen Schlüsse auf die Verhältnisse im Körper ziehen zu können. Und das ist der Punkt, den ich allerdings bestreite. Wenn eine Bacterie in irgend einer Cultur durch irgend ein Mittel am Wachsthum gehindert wird, ist daraus absolut kein Schluss auf die Verhältnisse im Körper zu ziehen. Der Beweis ist folgender: Ich nahm Sublimatlösungen in Blut von der 10 fachen Stärre, wie es Behring für seine Culturversuche verlangt, inficirte das Blut (genau wie Behring) mit Milzbrandsporen und injicirte es Thieren. Sie starben in der kürzesten Frist, die überhaupt vorkommt, an Milzbrand; nicht einmal eine Verzögerung war eingetreten.

An keiner einzigen Stelle dieses ganzen Aufsatzes verficht Behring den Gedanken, den er jetzt bei Besprechung meiner Arbeit äussert, dass die Resultate von Versuchen über Entwicklungshemmung nur für die Cultur gelten. Im Gegentheil, er weist diesen Einwurf als ganz unbegründet ab. Ich muss allerdings gestehen, dass ich eine Widerlegung dieses Einwandes in der Arbeit nicht gefunden habe, sondern nur die Versicherung, dass der Einwand unbegründet sei. (Schluss folgt.)

1) Ueber die Bestimmung des antiseptischen Werthes chemischer Präparate mit besonderer Berücksichtigung einiger Quecksilberpräparate von Stabsarzt Behring 1889 No. $41,42,43$

2) p. 869 (1. c.) definirt Behring die Begriffe ,entwicklungshemmend" und, antiseptisch" als gleichbedeutend; es sind in diesem Aufsatz auch nur Experimente über Entwicklungshemmung angeführt. 